\title{
INFORMATION SUPPORT SYSTEMS FOR CULTURAL HERITAGE PROTECTION AGAINST FLOODING
}

\author{
K. Nedvedova ${ }^{a}$, R. Pergl ${ }^{b}$ \\ ${ }^{\text {a }}$ Institute of Theoretical and Applied Mechanics, Academy of Science Czech Republic, Prosecká 76, Praha, Czech Republic - \\ nedvedova@itam.cas.cz \\ ${ }^{\mathrm{b}}$ Faculty of Economics and Management, Czech University of Life Sciences, Kamýcká 129, 16521 Praha 6, Czech Republic - \\ pergl@pef.czu.cz
}

KEY WORDS: Cultural Heritage, Flooding, Information Support Systems, Flood Protection Planning, Vulnerability Assessment, Open-source Software, Process Modeling

\begin{abstract}
:
The goal of this paper is to present use of different kind of software applications to create complex support system for protection of cultural heritage against flooding. The project is very complex and it tries to cover the whole area of the problem from prevention to liquidation of aftermath effects. We used GIS for mapping the risk areas, ontology systems for vulnerability assessment application and the BORM method (Business Object Relation Modelling) for flood protection system planning guide. Those modern technologies helped us to gather a lot of information in one place and provide the knowledge to the broad audience.
\end{abstract}

\section{INTRODUCTION}

Flood protection is a very hot topic nowadays though cultural heritage still lies on its outskirt. There is great need of interdisciplinary approach in planning of preventive measures as well as remedial work where not only technical but also cultural, esthetical and historical point of view would go into account (Nedvědová, 2013, 5/4A). We have to have in mind that each field of knowledge has only limited point of view and cultural heritage sites are very complex and require also a complex approach to solve the flood problem.

Awareness of value of authentic materials and evidence of traditional technology is very important. Effective instructions for owners and administrators of buildings but also for local authorities, what to do before, during, and after the flood, should be easily available. Education about most common mistakes and also good practice is highly necessary (Drdácký, Slížková, 2012).

\section{METHODOLOGY}

The research is based on former studies and research projects regarding the impact of flooding upon cultural heritage e.g. the European CHEF project (Cultural Heritage Protection against Flood), experience from floods in the past 20 years and knowledge of experts dealing with construction stability, humidity in constructions, biodegradation, changes of subsoil conditions, restoration of movable objects etc. Except collecting technical data about constructions and damages the interviews with owners, stakeholders and policy makers were done. Therefore the complex analysis of the main problems that occurred during and after the disastrous flooding could be achieved.

\footnotetext{
* Corresponding author
}

We decided to develop complex system for protection that would cover the whole process of o risk assessment, damage assessment, preventive measures (long term and short term) and finally dealing with the consequences after the disaster. As the area covered is very broad and processes are quite complex we needed some sophisticated modern tools to deal with the problem.

We decided not to focus only on one system but combine different types to achieve maximum efficiency. We choose GIS, ontological maps, semantic web, BORM etc. Open source software was the first choice due to its easy accessibility and possibility of implementation to other projects.

\section{RESULTS}

\subsection{Map application}

Geographical positioning of cultural heritage objects in relation to flood zones is starting point of risk assessment. All the data already existed but their availability was very complicated and one would have to combine several sources to get the required information. Therefore the task was to create a web application where users could easily localize the building according to its address and directly see the borders of the flood zones.

We used spatial localization of cultural heritage monuments and sites, building address catalogue and spatial demarcation of HQ5, 20, 100 and in some cases also of the biggest flood that occurred in the area in the past. Those three heterogeneous data sources were imported into a GIS server using algorithms based on spatial proximity and spatial relations in order to create integrated information system. The key code for connection to original database is kept for further link to other data. Therefore you can look into database of National Heritage Institute for additional information about each monument. All listed 
buildings of cultural heritage as well as protected areas are highlighted and coloured by degree of flood danger.

The software solution consists of three components (Figure 1): the PostGIS database running on the top of PostgreSQL, the REST server implemented in Node.JS and a client HTML/CSS/Javascript application based on Leaflet.JS library and Mapbox tiling server. With the exception of the Mapbox dependency, all the technologies are open-source. In case of need, Mapbox may be replaced by OpenStreet maps.

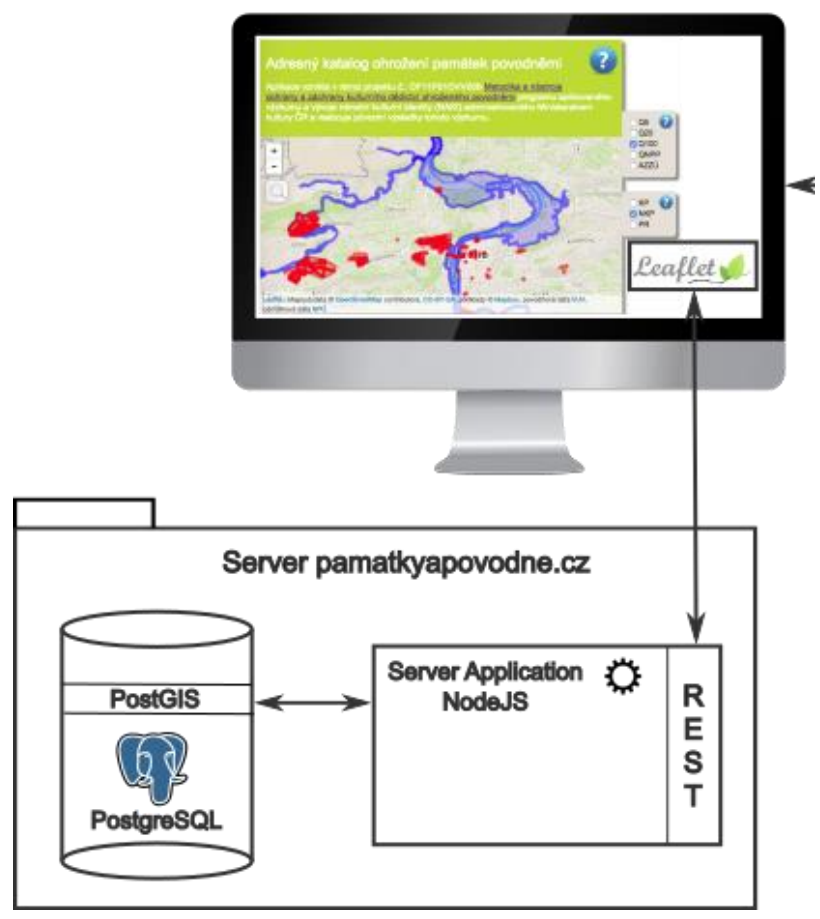

Figure 1. Map application architecture

\subsection{Vulnerability assessment application}

Next step in successful risk assessment is vulnerability analysis concerning building constructions and their materials. Detailed knowledge of building history, its construction system, surrounding terrain, soil and climate conditions increase effectiveness of preventive measures, protection and preserving of cultural heritage.

The vulnerability assessment application was developed using standard software engineering approach (Beck, 1998) and it was inspired by Agile methodologies. The architecture consists of the expert application for inputting knowledge data and the user application for utilizing this data.

The expert application is a typical client-server web application. The first version of the server was developed using the opensource Django web development framework and the persistence was managed by the PostgreSQL database. The second version, which contains complex analysis tables was re-developed using pure object-oriented open-source technology Pharo (http://pharo.org) and the Seaside framework (http://www.seaside.st). The whole solution is hosted on a Ubuntu Server machine. The system is open so it may be updated and new information can be added.
The core of the system is the ability to offer multi-view analysis relation tables for inputting of the expert knowledge. These tables are generated from the lists of values (LoV) administered in the system database. Each relation holds arbitrary attributes. The user interface facilitates operations like copy-paste of cells and columns. Currently, there are two main analysis tables in the system:

- Construction types + materials vs. specific influences - This table expresses impact of various influences like the flood characteristics and weather on certain construction types and materials. The relation holds the information about the possible construction failures, prevention measures and mitigation of failures.

- Mutual influence of construction types - a failure of one construction often may case a failure of another one. This table holds information about the mutual relations.

The user application (Figure 2) is focused on public users. It is also implemented as a client-server application. The server part is mostly a REST service providing data from the expert application to the client part. The client part is built using the Clojurescript programming language that compiles into Javascript. Client-focused implementation enables high interactivity, user friendliness and attractiveness for end users.

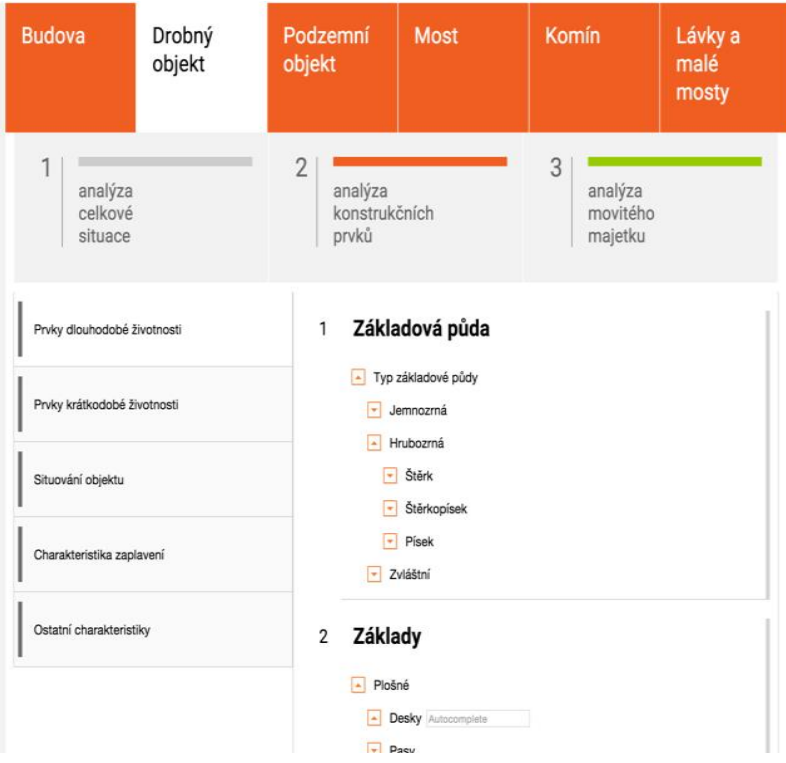

Figure 2. A sample of interactive web user interface of the

Vulnerability Assessment

\subsection{Flood protection system planning tool}

The aim of the last part of the project is development of guidelines for suitable design of flood preventive measures (FPM) and their integration to the cultural landscape and historical urban areas. This requires improving cooperation among partial subjects in the planning process. The output of this phase is software that will be able to track the whole process from the very beginning to the actual realization of the specific construction.

Planning of flood protection systems is very complex task. A lot of factors need to be taken into account and a lot of participants have to be coordinated. Usually main role is up to water 
management engineers. But we have found that results are often insufficient especially when heritage sites are in danger as the solution is concerning just technical and economical point of view. Therefore we decided to draw attention to other aspects by creating an ontological model of cultural, historical, functional and spatial values of the site, including stakeholders and their interests.

The software solution for optimising project coordination is based on the features of the issue, which is a workflow system. It consists of various participants performing certain roles. Individual participants' actions and states are important for the whole process success. The preliminary analysis shows that communications between participants are of paramount importance. Other features include document storage, timing and deadline characteristics, audit trail and logs.

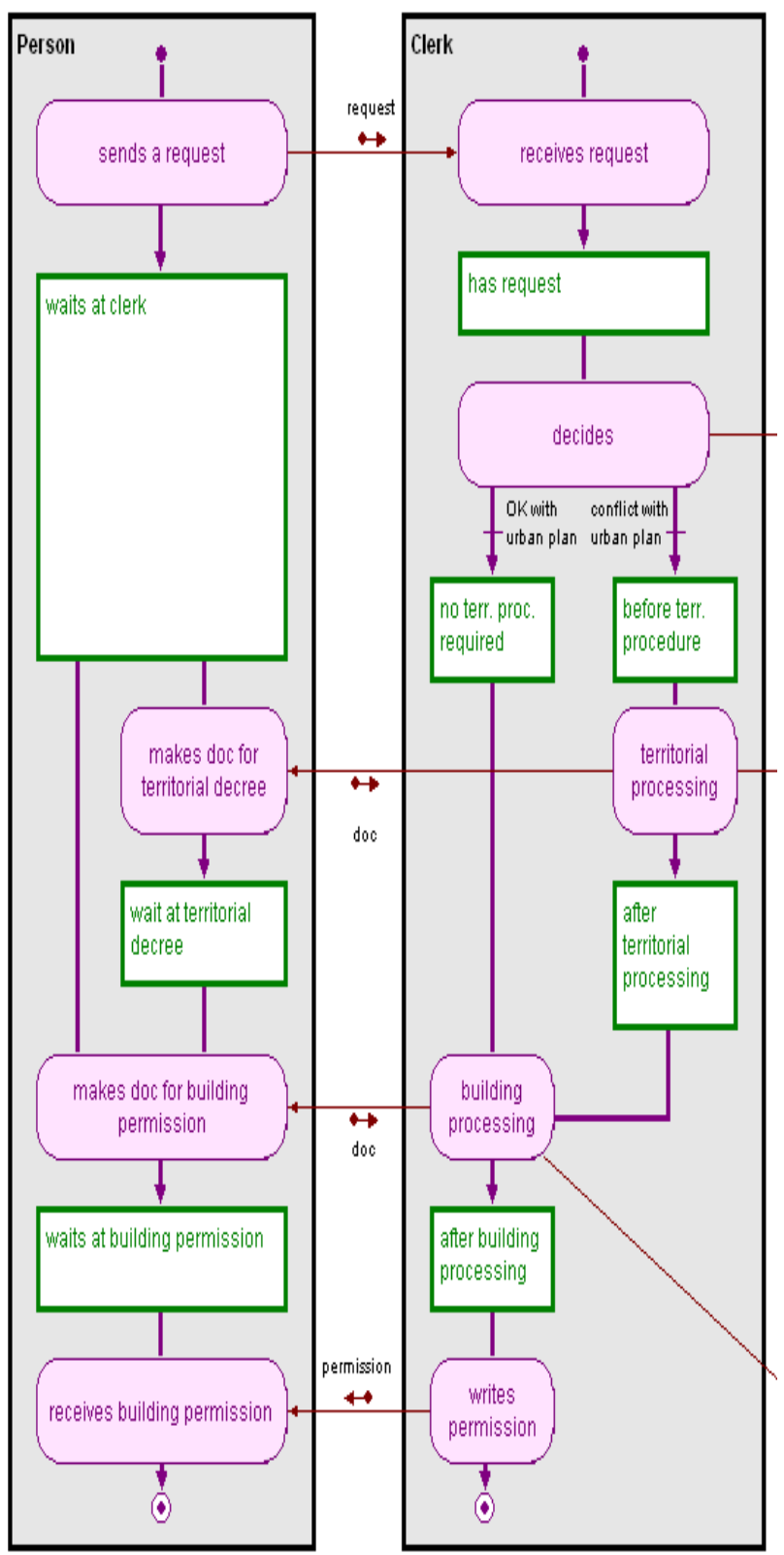

Figure 3. Example of business process as a cooperation of participating objects described by state machines (Merunková, 2014)
Based on our long-year experience, we decided to apply the BORM method. Business Object Relation Modelling (BORM) (Liping, Roussev, 2005) is a complex method for systems analysis and design that utilizes an object oriented paradigm in combination with business process modelling. It originated at the Loughborough University, UK in 1993. Successful utilizations have been reported and published ever since, mostly for orchestration-intensive systems of several socio-technical projects related to the work-flow systems, industrial, business and governmental processes, self-administration and law. BORM provides process workflow formalization that is similar to BPMN (Silver, 2011), however it is ontologically better founded. The basic idea of BORM approach is the combination of the object-oriented paradigm and theory of finite-state machines (theory of automata). BORM process decomposition is based on a set of more mutually communicating Mealy-type automata representing independent process participants in their states and activities.

Thus, we are building the project coordination support system based on the BORM orchestration. The system is built on client-server architecture. The server is hosting BORM diagrams, users and other data, while a thin web client application is providing a portal solution where participants will be able to $\log$ in and operate in the workflow. Individual process diagrams are graphically animated during the simulation. Individual users have different access rights from the full process control to simple viewing.

\section{CONCLUSION}

Although floods are usually short-term events, it takes a very long time and enormous effort to deal with the consequences. Cultural heritage forms special category that requires usually unique and individual approach because its assets cannot be reproduced in contrary to ordinary buildings and objects. Irreversible loss and great expenses spent to restoration and renewal is calling for integrated flood risk management. Application of modern software tools enables better coordination and communication between experts and vast accessibility of professional knowledge to the public. Open source software could be a good and sufficient choice even for complicated processes and is irreplaceable for such kind of a project where potential adaptation is expected.

\section{AKNOWLEDGEMENT}

The research has been supported by the research grant NAKI DF11PO1OVV009 provided by MK ČR.

\section{REFERENCES}

Beck, K., 1998. Process Patterns: Building Large-Scale Systems Using Object Technology. Cambridge University Press.

Drdácký, M., Slížková, Z., 2012. Structural strategies and measures reducing flood action on architectural heritage. In "Risk Analysis VIII" (C.A. Brebbia - ed.), ISBN: 978-1-84564620-2, eISBN: 978-1-84564-621-9, ISSN (print): 1746-4463, ISSN (online): 1743-3517, WIT Transactions on Information and Communication Technologies, Vol 44, WIT Press, Ashurst, Southampton, UK, pp. 249-259, doi:10.2495/RISK120221. 
Liping, L. and Roussev, B. eds., 2005. "The BORM Method: A Third Generation Object-Oriented Methodology." Management of the Object-Oriented Development Process: IGI Global.

Merunková, I., 2014, Územní plánování pro zvýšení kvality života ve venkovském prostoru. Dissertation thesis, PEF ČZU in Prague, February.

Nedvědová, K., April 2013. Cultural Heritage and Flood - Need of Interdisciplinarity. In Journal of Water Resource and Protection, Vol. 5, No. 4A, (Special Issue on Water: Unite and Divide).

Silver, B., 2011. BPMN Method and Style, 2nd Edition, with BPMN Implementer's Guide: A Structured Approach for Business Process Modeling and Implementation Using BPMN 2.0. Cody-Cassidy Press. 